\title{
Theoretical study on the nature of Gold-X(IVA) interaction
}

\author{
Wanli Zhang ${ }^{1}$ and Xinying $\operatorname{Li}^{1}$ \\ ${ }^{1}$ Henan University
}

November 1, 2021

\begin{abstract}
Structures, stabilities, and interactions of $\mathrm{AuX}(\mathrm{X}=\mathrm{C}-\mathrm{Pb})$ series are theoretically investigated at CCSD $(\mathrm{T})$ and B3LYP levels with extend basis sets. Natural bond orbital analysis shows that the Au-X interaction is resulted by the overlap of sp hybrid on X and 6s5d hybrid on Au atom. Laplacian and total electronic energy density values at BCP shows the "intermediate type" of $\mathrm{Au}-\mathrm{X}(\mathrm{X}=\mathrm{Si}, \mathrm{Ge}, \mathrm{Sn}, \mathrm{Pb})$ interactions and covalent type of Au-C interaction. Moreover, analysis of electron density deformation shows pronounced charge accumulation in the middle of the region between lighter $\mathrm{X}$ and Au, suggesting obvious covalent character of interaction. ELF shows increased covalency from $\mathrm{X}=\mathrm{Pb}$ to $\mathrm{X}=\mathrm{C}$. Energy decomposition analysis shows positive steric contribution and negative quantum contributions to the $\mathrm{Au}-\mathrm{X}$ interactions. Comparing the interaction energy of $\mathrm{AuC}$ with other AuX series, the decrease of interaction strength between them is caused by the positive contribution of steric effect and the negative contribution of quantum and electrostatic effects. Steric charge distribution shows interaction type causes effects to distribution of steric charge. And steric energy is correlated positively with the total interaction energy and correlated positively with the steric charge deformation at BCP.
\end{abstract}

\section{Hosted file}

Manuscript.docx available at https://authorea.com/users/444064/articles/543885-theoreticalstudy-on-the-nature-of-gold-x-iva-interaction 